\title{
Fixed point results for multivalued mappings on a sequence in a closed ball with applications
}

\author{
Abdullah Shoaib ${ }^{\mathrm{a}, *}$, Akbar Azam $^{\mathrm{b}}$, Muhammad Arshad $^{\mathrm{c}}$, Eskandar Ameer ${ }^{\mathrm{c}, \mathrm{d}}$ \\ ${ }^{a}$ Department of Mathematics and Statistics, Riphah International University, Islamabad - 44000, Pakistan. \\ ${ }^{b}$ Department of Mathematics, COMSATS Institute of Information Technology, Chack Shahzad, Islamabad - 44000, Pakistan. \\ ${ }^{c}$ Department of Mathematics, International Islamic University, $\mathrm{H}-10$, Islamabad - 44000, Pakistan. \\ ${ }^{d}$ Department of Mathematics, Taiz University, Taiz, Yemen.
}

\begin{abstract}
In this paper, we establish fixed point results for semi $\alpha_{*}$-admissible multivalued mappings satisfying a contractive condition of Reich type only for the elements in a sequence contained in closed ball in a complete dislocated metric space. As an application, we derive some new fixed point theorems for ordered metric space and metric space endowed with a graph. An example has been constructed to demonstrate the novelty of our results. Our results unify, extend, and generalize several comparable results in the existing literature. (C)2017 All rights reserved.
\end{abstract}

Keywords: Fixed point, complete dislocated metric space, closed ball, semi $\alpha_{*}$-admissible.

2010 MSC: 46S40, 47H10, 54H25.

\section{Introduction and preliminaries}

Let $S: X \longrightarrow X$ be a mapping. A point $x \in X$ is called a fixed point of $S$ if $x=S x$. Many results appeared in literature related to the fixed point of mappings which are contractive on the whole domain. It is possible that $S: X \longrightarrow X$ is not a contraction but $S: Y \longrightarrow X$ is a contraction, where $Y$ is a closed ball in $X$. One can obtain fixed point results for such mapping by using suitable conditions. Recently, Hussain et al. [14] proved a result concerning the existence of fixed points of a mapping satisfying a contractive condition on closed ball (see also [3-6, 28-30]).

The notion of dislocated topologies have useful applications in the context of logic programming semantics (see [12]). Dislocated metric space (metric-like space) (see [2, 17, 25]) is a generalization of partial metric space (see [19, 26]). Karapinar et al. [17] noticed that the notions metric-like space [2] and dislocated metric space [12] are exactly the same. They also discussed the existence and uniqueness of a fixed point of a cyclic mapping in the context of metric-like spaces. Arshad et al. [5, 21, 22] noticed that the closed ball, Cauchy sequence, and completeness defined on these spaces are different from each other.

\footnotetext{
*Corresponding author

Email addresses: abdullahshoaib15@yahoo.com (Abdullah Shoaib), akbarazam@yahoo.com (Akbar Azam), marshadzia@iiu.edu.pk (Muhammad Arshad), eskandarameer@yahoo.com (Eskandar Ameer)

doi:10.22436/jmcs.017.02.13
} 
They remarked that it is better to find a fixed point in a closed ball in dislocated metric space. They also gave an example of a space which was complete dislocated metric space but was not complete metric-like space.

Nadler [20], introduced a study of fixed point theorems involving multivalued mappings (see also $[8,9])$. The existence of fixed points of $\alpha$-admissible mappings in complete metric spaces has been studied by several researchers (see [18, 23, 27]). Asl et al. [7] generalized these notions by introducing the concepts of $\alpha_{*}-\psi$ contractive multifunctions, $\alpha_{*}$-admissible mapping and obtained some fixed point results for these multifunctions (see also [1, 13, 15]). On the other hand, [24] established some results concerning contraction mappings. In this paper we discuss some new fixed point results for Reich type multivalued mappings in a closed ball in complete dislocated metric space.

The following definitions and results will be needed in the sequel.

Definition $1.1([5,17])$. Let $X$ be a nonempty set and let $d_{l}: X \times X \rightarrow[0, \infty)$ be a function, called a dislocated metric (or simply $\mathrm{d}_{\mathrm{l}}$-metric), if for any $x, y, z \in X$, the following conditions hold:

(i) if $d_{l}(x, y)=0$, then $x=y$;

(ii) $d_{l}(x, y)=d_{l}(y, x)$;

(iii) $d_{l}(x, y) \leqslant d_{l}(x, z)+d_{l}(z, y)$.

The pair $\left(X, d_{l}\right)$ is called a dislocated metric space.

It is clear that if $d_{l}(x, y)=0$, then from (i), $x=y$. But if $x=y, d_{l}(x, y)$ may not be 0 . For $x \in X$ and $\varepsilon>0, \overline{B(x, \varepsilon)}=\left\{y \in X: d_{l}(x, y) \leqslant \varepsilon\right\}$ is a closed ball in $\left(X, d_{l}\right)$.

Example 1.2 ([5]). If $X=R^{+} \cup\{0\}$, then $d_{l}(x, y)=x+y$ defines a dislocated metric $d_{l}$ on $X$.

Definition $1.3([5])$. Let $\left(X, d_{l}\right)$ be a dislocated metric space.

(i) A sequence $\left\{x_{n}\right\}$ in $\left(X, d_{l}\right)$ is called Cauchy sequence if given $\varepsilon>0$, there corresponds $n_{0} \in N$ such that for all $n, m \geqslant n_{0}$ we have $d_{l}\left(x_{m}, x_{n}\right)<\varepsilon$ or $\lim _{n, m \rightarrow \infty} d_{l}\left(x_{n}, x_{m}\right)=0$.

(ii) A sequence $\left\{x_{n}\right\}$ dislocated-converges (for short $d_{l}$-converges) to $x$ if $\lim _{n \rightarrow \infty} d_{l}\left(x_{n}, x\right)=0$. In this case $x$ is called a $d_{l}$-limit of $\left\{x_{n}\right\}$.

(iii) $\left(X, d_{l}\right)$ is called complete if every Cauchy sequence in $X$ converges to a point $X \in X$ such that $\mathrm{d}_{l}(x, x)=0$.

Definition 1.4. Let $K$ be a nonempty subset of dislocated metric space $X$ and let $x \in X$. An element $y_{0} \in K$ is called a best approximation in $\mathrm{K}$ if

$$
d_{l}(x, K)=d_{l}\left(x, y_{0}\right), \text { where } d_{l}(x, K)=\inf _{y \in K} d_{l}(x, y) .
$$

If each $x \in X$ has at least one best approximation in $K$, then $K$ is called a proximinal set.

We denote $\mathrm{CP}(\mathrm{X})$ be the set of all closed proximinal subsets of $\mathrm{X}$. Let $\Psi$ denote the family of all nondecreasing functions $\psi:[0,+\infty) \rightarrow[0,+\infty)$ such that $\sum_{n=1}^{+\infty} \psi^{n}(t)<+\infty$ for all $t>0$, where $\psi^{n}$ is the $\mathrm{n}^{\text {th }}$ iterate of $\psi$. If $\psi \in \Psi$, then $\psi(t)<t$ for all $t>0$.

Definition 1.5. Let $S: X \rightarrow P(X)$ be a multivalued mapping and $\alpha: X \times X \rightarrow[0,+\infty)$. Let $A \subseteq X$, we say that $S$ is semi $\alpha_{*}$-admissible on $A$, whenever $\alpha(x, y) \geqslant 1$ implies that $\alpha_{*}(S x, S y) \geqslant 1$ for all $x, y \in A$, where $\alpha_{*}(S x, S y)=\inf \{\alpha(a, b): a \in S x, b \in S y\}$. If $A=X$, then we say that $S$ is $\alpha_{*}$-admissible on $X$.

Definition 1.6. The function $H_{d_{l}}: P(X) \times P(X) \rightarrow X$, defined by

$$
H_{d_{l}}(A, B)=\max \left\{\sup _{a \in A} d_{l}(a, B), \sup _{b \in B} d_{l}(A, b)\right\}
$$

is called dislocated Hausdorff-Pompeiu metric on $P(X)$. Also, $\left(P(X), H_{d_{q}}\right)$ is known as dislocated quasi Hausdorff-Pompeiu metric space. 
Lemma 1.7. Let $\left(\mathrm{X}, \mathrm{d}_{\mathrm{l}}\right)$ be a dislocated metric space. Let $\left(\mathrm{P}(\mathrm{X}), \mathrm{H}_{\mathrm{d}_{l}}\right)$ is a dislocated Hausdorff-Pompeiu metric space on $P(X)$. Then for all $A, B \in C P(X)$ and for each $a \in A$ there exists $b_{a} \in B$ satisfying $d_{l}(a, B)=d_{l}\left(a, b_{a}\right)$, then $\mathrm{H}_{\mathrm{d}_{\mathrm{l}}}(A, B) \geqslant \mathrm{d}_{\mathrm{l}}\left(\mathrm{a}, \mathrm{b}_{\mathrm{a}}\right)$.

Proof. If $H_{d_{l}}(A, B)=\sup _{a \in A} d_{l}(a, B)$, then $H_{d_{l}}(A, B) \geqslant d_{l}(a, B)$ for each $a \in A$. As $B$ is a proximinal set, so for each $a \in X$, there exists at least one best approximation $b_{a} \in B$ that satisfies $d_{l}(a, B)=d_{l}\left(a, b_{a}\right)$. Now we have, $H_{d_{l}}(A, B) \geqslant d_{l}\left(a, b_{a}\right)$. Now $H_{d_{l}}(A, B)=\sup _{b \in B} d_{l}(A, b) \geqslant \sup _{a \in A} d_{l}(a, B)$, hence, the lemma is proved.

\section{Main result}

Let $\left(X, d_{l}\right)$ be a dislocated metric space, $x_{0} \in X$ and $S: X \rightarrow P(X)$ be a multivalued mapping on $X$. Then there exists $x_{1} \in S x_{0}$ such that $d_{l}\left(x_{0}, S x_{0}\right)=d_{l}\left(x_{0}, x_{1}\right)$. Let $x_{2} \in S x_{1}$ be such that $d_{l}\left(x_{1}, S x_{1}\right)=$ $d_{l}\left(x_{1}, x_{2}\right)$. Continuing this process, we construct a sequence $x_{n}$ of points in $X$ such that $x_{n+1} \in S x_{n}$ and $d_{l}\left(x_{n}, S x_{n}\right)=d_{l}\left(x_{n}, x_{n+1}\right)$. We denote this iterative sequence $\left\{X S\left(x_{n}\right)\right\}$ and say that $\left\{X S\left(x_{n}\right)\right\}$ is a sequence in $X$ generated by $x_{0}$.

Theorem 2.1. Let $\left(X, d_{l}\right)$ be a complete dislocated metric space, $r>0, x_{0} \in \overline{B_{d_{l}}\left(x_{0}, r\right)} \alpha: X \times X \longrightarrow[0,+\infty)$, $\mathrm{S}: \mathrm{X} \rightarrow \mathrm{P}(\mathrm{X})$ be a semi $\alpha_{*}$-admissible multifunction on $\overline{\mathrm{B}_{\mathrm{d}_{l}}\left(\mathrm{x}_{0}, \mathrm{r}\right)}$ and $\left\{\mathrm{XS}\left(\mathrm{x}_{\mathrm{n}}\right)\right\}$ be a sequence in $\mathrm{X}$ generated by $\mathrm{x}_{0}, \alpha\left(\mathrm{x}_{0}, \mathrm{x}_{1}\right) \geqslant 1$. Suppose that there exist $\mathrm{a}, \mathrm{b} \in[0,1)$ with $\mathrm{a}+2 \mathrm{~b}<1$ such that

$$
\alpha_{*}(S x, S y) H_{d_{l}}(S x, S y) \leqslant a d_{l}(x, y)+b\left[d_{l}(x, S x)+d_{l}(y, S y)\right]
$$

for all $x, y \in \overline{\mathrm{B}_{\mathrm{d}_{l}}\left(\mathrm{x}_{0}, \mathrm{r}\right)} \cap\left\{\mathrm{XS}\left(\mathrm{x}_{\mathrm{n}}\right)\right\}$, and

$$
d_{l}\left(x_{0}, S x_{0}\right) \leqslant(1-\lambda) r, \text { where } \lambda=\frac{a+b}{1-b} .
$$

Then $\left\{\mathrm{XS}\left(\mathrm{x}_{\mathrm{n}}\right)\right\}$ is a sequence in $\overline{\mathrm{B}_{\mathrm{d}_{l}}\left(\mathrm{x}_{0}, \mathrm{r}\right)}$ and $\left\{\mathrm{XS}\left(\mathrm{x}_{\mathrm{n}}\right)\right\} \rightarrow \mathrm{x}^{*} \in \overline{\mathrm{B}_{\mathrm{d}_{l}}\left(\mathrm{x}_{0}, \mathrm{r}\right)}$ and $\alpha\left(\mathrm{x}_{\mathrm{n}}, \mathrm{x}_{\mathrm{n}+1}\right) \geqslant 1$ for $\mathrm{x}_{\mathrm{n}}, \mathrm{x}_{\mathrm{n}+1} \in$ $\left\{X S\left(x_{n}\right)\right\}, n \in \mathbb{N} \cup\{0\}$. Also, if $\alpha\left(x_{n}, x^{*}\right) \geqslant 1$ or $\alpha\left(x^{*}, x_{n}\right) \geqslant 1$ for all $n \in \mathbb{N} \cup\{0\}$ and inequality (2.1) holds for all $x, y \in\left(\overline{\mathrm{B}_{\mathrm{d}_{\mathrm{l}}}\left(\mathrm{x}_{0}, \mathrm{r}\right)} \cap\left\{\mathrm{XS}\left(\mathrm{x}_{\mathrm{n}}\right)\right\}\right) \cup\left\{\mathrm{x}^{*}\right\}$, then $\mathrm{S}$ has a fixed point in $\overline{\mathrm{B}_{\mathrm{d}_{\mathrm{l}}}\left(\mathrm{x}_{0}, \mathrm{r}\right)}$.

Proof. As $x_{0} \in \overline{B_{d_{l}}\left(x_{0}, r\right)}$, and $S: X \rightarrow P(X)$ is a multivalued mapping on $X$, then there exists $x_{1} \in S x_{0}$ such that $d_{l}\left(x_{0}, S x_{0}\right)=d_{l}\left(x_{0}, x_{1}\right)$. If $x_{0}=x_{1}$, then $x_{0}$ is a fixed point in $\overline{B_{d_{l}}\left(x_{0}, r\right)}$ of $S$. Let $x_{0} \neq x_{1}$. From (2.2), we get,

$$
\mathrm{d}_{\mathrm{l}}\left(\mathrm{x}_{0}, \mathrm{x}_{1}\right) \leqslant(1-\lambda) \mathrm{r}<\mathrm{r} .
$$

It follows that $x_{1} \in \overline{\mathrm{B}_{\mathrm{d}_{l}}\left(x_{0}, r\right)}$. As $\alpha\left(x_{0}, x_{1}\right) \geqslant 1$ and $S$ is semi $\alpha_{*}$-admissible multifunction on $\overline{\mathrm{B}_{\mathrm{d}_{l}}\left(\mathrm{x}_{0}, r\right)}$, so $\alpha_{*}\left(S x_{0}, S x_{1}\right) \geqslant 1$. As $\alpha_{*}\left(S x_{0}, S x_{1}\right) \geqslant 1, x_{1} \in S x_{0}$ and $x_{2} \in S x_{1}$, so $\alpha\left(x_{1}, x_{2}\right) \geqslant 1$. As $S$ is semi $\alpha_{*}$-admissible multifunction on $\overline{\mathrm{B}_{\mathrm{d}_{l}}\left(\mathrm{x}_{0}, \mathrm{r}\right)}$, thus, we have $\alpha_{*}\left(S x_{1}, S x_{2}\right) \geqslant 1$. As $\alpha_{*}\left(S x_{1}, S x_{2}\right) \geqslant 1$, we have $\alpha\left(x_{2}, x_{3}\right) \geqslant 1$, which further implies $\alpha_{*}\left(S x_{2}, S x_{3}\right) \geqslant 1$. Continuing this process, we have $\alpha_{*}\left(S x_{j-1}, S x_{j}\right) \geqslant 1$. Now,

$$
\begin{aligned}
d_{l}\left(x_{j}, x_{j+1}\right) \leqslant H_{d_{l}}\left(S x_{j-1}, S x_{j}\right) & \leqslant \alpha_{*}\left(S x_{j-1}, S x_{j}\right) H_{d_{l}}\left(S x_{j-1}, S x_{j}\right) \\
& \leqslant a d_{l}\left(x_{j-1}, x_{j}\right)+b\left[d_{l}\left(x_{j-1}, S x_{j-1}\right)+d_{l}\left(x_{j}, S x_{j}\right)\right] \\
& =a d_{l}\left(x_{j-1}, x_{j}\right)+b d_{l}\left(x_{j-1}, x_{j}\right)+b d_{l}\left(x_{j}, x_{j+1}\right) \\
& \leqslant(a+b) d_{l}\left(x_{j-1}, x_{j}\right)+b d_{l}\left(x_{j}, x_{j+1}\right) \\
& \leqslant \frac{a+b}{1-b} d_{l}\left(x_{j-1}, x_{j}\right)=\lambda d_{l}\left(x_{j-1}, x_{j}\right) \leqslant \cdots \leqslant \lambda^{j} d_{l}\left(x_{0}, x_{1}\right),
\end{aligned}
$$

which implies,

$$
d_{l}\left(x_{j}, x_{j+1}\right) \leqslant \lambda^{j} d_{l}\left(x_{0}, x_{1}\right)
$$


Now,

$$
\begin{aligned}
d_{l}\left(x_{0}, x_{j+1}\right) & \leqslant d_{l}\left(x_{0}, x_{1}\right)+\cdots+d_{l}\left(x_{j}, x_{j+1}\right) \\
& \leqslant d_{l}\left(x_{0}, x_{1}\right)+\cdots+\lambda^{j} d_{l}\left(x_{0}, x_{1}\right) \\
& =\left(1+\lambda+\cdots+\lambda^{j}\right) d_{l}\left(x_{0}, x_{1}\right) \\
& \leqslant(1-\lambda)\left(1+\lambda+\cdots+\lambda^{j}\right) r<r .
\end{aligned}
$$

Thus $x_{j+1} \in \overline{B_{d_{l}}\left(x_{0}, r\right)}$. Hence by induction, $x_{n} \in \overline{B_{d_{l}}\left(x_{0}, r\right)}$ and $\alpha\left(x_{n}, x_{n+1}\right) \geqslant 1$ for all $n \in \mathbb{N}$. As $S$ is semi $\alpha_{*}$-admissible multifunction on $\overline{B_{d_{l}}\left(x_{0}, r\right)}$, therefore $\alpha_{*}\left(S x_{n}, S x_{n+1}\right) \geqslant 1$ for all $n \in \mathbb{N} \cup\{0\}$. Now inequality (2.3) can be written as

$$
d_{l}\left(x_{n}, x_{n+1}\right) \leqslant \lambda^{n} d_{l}\left(x_{0}, x_{1}\right) \text { for all } n \in N .
$$

Now,

$$
d_{l}\left(x_{n}, x_{n+i}\right) \leqslant d_{l}\left(x_{n}, x_{n+1}\right)+\ldots+d_{l}\left(x_{n+i-1}, x_{n+i}\right) \leqslant \frac{\lambda^{n}\left(1-\lambda^{i}\right)}{1-\lambda} d_{l}\left(x_{0}, x_{1}\right) \longrightarrow 0 \text { as } n \rightarrow \infty .
$$

Thus, we proved that $\left\{x_{n}\right\}$ is a Cauchy sequence in $\left(\overline{B_{d_{l}}\left(x_{0}, r\right)}, d_{l}\right)$. As every closed ball in a complete dislocated metric space is complete, so there exists $x^{*} \in \overline{B_{d_{l}}\left(x_{0}, r\right)}$ such that $x_{n} \rightarrow x^{*}$, and

$$
\lim _{n \rightarrow \infty} d_{l}\left(x_{n}, x^{*}\right)=0 .
$$

Hence $\left\{X S\left(x_{n}\right)\right\}$ is a sequence in $\overline{B_{d_{l}}\left(x_{0}, r\right)}$ generated by $x_{0}$ and $\left\{X S\left(x_{n}\right)\right\} \rightarrow x^{*} \in \overline{B_{d_{l}}\left(x_{0}, r\right)}$ and $\alpha\left(x_{n}, x_{n+1}\right) \geqslant$ 1 for $x_{n}, x_{n+1} \in\left\{X S\left(x_{n}\right)\right\}, n \in \mathbb{N} \cup\{0\}$. As $\alpha_{*}\left(S x_{n}, S x_{n+1}\right) \geqslant 1$ for all $n \in \mathbb{N} \cup\{0\}$, we have $\alpha\left(x_{n+1}, x_{n+2}\right) \geqslant$ 1 for all $n \in \mathbb{N} \cup\{0\}$. By assumption, we have $\alpha\left(x_{n}, x^{*}\right) \geqslant 1$ for all $n \in \mathbb{N} \cup\{0\}$. Thus $\alpha_{*}\left(S x_{n}, S x^{*}\right) \geqslant 1$. Now,

$$
\begin{aligned}
d_{l}\left(x^{*}, S x^{*}\right) & \leqslant d_{l}\left(x^{*}, x_{n+1}\right)+d_{l}\left(x_{n+1}, S x^{*}\right) \\
& \leqslant d_{l}\left(x^{*}, x_{n+1}\right)+H_{d_{l}}\left(S x_{n}, S x^{*}\right) \\
& \leqslant d_{l}\left(x^{*}, x_{n+1}\right)+\alpha_{*}\left(S x_{n}, S x^{*}\right) H_{d_{l}}\left(S x_{n}, S x^{*}\right) \\
& \leqslant d_{l}\left(x^{*}, x_{n+1}\right)+a_{l}\left(x_{n}, x^{*}\right)+b\left[d_{l}\left(x_{n}, S x_{n}\right)+d_{l}\left(x^{*}, S x^{*}\right)\right] .
\end{aligned}
$$

Letting $n \rightarrow \infty$ in the previous inequality, by using inequality (2.4) and (2.5), we get

$$
(1-b) d_{l}\left(x^{*}, S x^{*}\right) \leqslant 0 .
$$

Similarly, if $\alpha\left(x^{*}, x_{n}\right) \geqslant 1$ for all $n \in N \cup\{0\}$, thus $\alpha_{*}\left(S x^{*}, S x_{n}\right) \geqslant 1$. Now,

$$
(1-b) d_{l}\left(S x^{*}, x^{*}\right) \leqslant 0 .
$$

We obtain, $d_{l}\left(S x^{*}, x^{*}\right)=0$. Hence $x^{*} \in S x^{*}$. So $S$ has a fixed point in $\overline{B_{d_{l}}\left(x_{0}, r\right)}$.

Let $X$ be a nonempty set. Then $\left(X, \preceq, d_{l}\right)$ is called a preordered dislocated metric space if $d_{l}$ is a dislocated metric on $X$ and is a preorder on $X$. Let $\left(X, \preceq, d_{l}\right)$ be a preordered metric space and $A, B \subseteq X$. We say that $A \preceq B$ whenever for each $a \in A$ there exists such that $a \preceq b$. Also, we say that $A \preceq r B$ whenever for each $a \in A$ and $b \in B$, we have $a \preceq b$.

Corollary 2.2. Let $\left(X, \preceq, \mathrm{d}_{\mathrm{l}}\right)$ be a preordered complete dislocatedmetric space, $\mathrm{r}>0, \mathrm{x}_{0} \in \overline{\mathrm{B}_{\mathrm{d}_{\mathrm{l}}}\left(\mathrm{x}_{0}, \mathrm{r}\right)}, \mathrm{S}: \mathrm{X} \rightarrow \mathrm{P}(\mathrm{X})$ and $\left\{\mathrm{XS}\left(\mathrm{x}_{\mathrm{n}}\right)\right\}$ be a sequence in $\mathrm{X}$ generated by $\mathrm{x}_{0}$ with $\mathrm{x}_{0} \preceq \mathrm{x}_{1}$. Suppose there exist $\mathrm{a}, \mathrm{b} \in[0,1)$ with $\mathrm{a}+2 \mathrm{~b}<1$ such that

$$
H_{d_{l}}(S x, S y) \leqslant a_{l}(x, y)+b\left[d_{l}(x, S x)+d_{l}(y, S y)\right]
$$


for all $x, y$ in $\overline{\mathrm{B}_{\mathrm{d}_{l}}\left(\mathrm{x}_{0}, \mathrm{r}\right)} \cap\left\{\mathrm{XS}\left(\mathrm{x}_{\mathrm{n}}\right)\right\}$ with $\mathrm{x} \preceq \mathrm{y}$, and

$$
d_{l}\left(x_{0}, S x_{0}\right) \leqslant(1-\lambda) r, \text { where } \lambda=\frac{a+b}{1-b} .
$$

If $x \preceq y$ implies $S x \preceq r$ Sy for all $x, y \in \overline{\mathrm{B}_{d_{l}}\left(x_{0}, r\right)} \cap\left\{X S\left(x_{n}\right)\right\}$, then $\left\{X S\left(x_{n}\right)\right\}$ is a sequence in $\overline{\mathrm{B}_{d_{l}}\left(x_{0}, r\right)}$, $x_{n} \preceq x_{n+1}$ and $\left\{X S\left(x_{n}\right)\right\} \rightarrow x^{*} \in \overline{\mathrm{B}_{d_{l}}\left(x_{0}, r\right)}$. Also if $x^{*} \preceq x_{n}$ or $x_{n} \preceq x^{*}$ for all $n \in \mathbb{N} \cup\{0\}$ and inequality (2.6) holds for all $x, y \in\left(\overline{\mathrm{B}_{\mathrm{d}_{l}}\left(x_{0}, r\right)} \cap\left\{X S\left(x_{n}\right)\right\}\right) \cup\left\{x^{*}\right\}$, then $x^{*}$ is a fixed point of $S$ in $\overline{\mathrm{B}_{\mathrm{d}_{l}}\left(x_{0}, r\right)}$.

Let $f: X \longrightarrow X$ be a self-mapping of a set $X$ and $\alpha: X \times X \rightarrow[0,+\infty)$ be a mapping, then the mapping $f$ is called semi $\alpha$-admissible if, $A \subseteq X, x, y \in A, \alpha(x, y) \geqslant 1$ implies $\alpha(f x, f y) \geqslant 1$. If $A=X$, then the mapping $f$ is called $\alpha$-admissible.

Corollary 2.3. Let $\left(X, \mathrm{~d}_{l}\right)$ be a complete dislocated metric space and $\mathrm{S}: \mathrm{X} \rightarrow \mathrm{X}, \mathrm{r}>0$ and $\mathrm{X}_{0}$ be an arbitrary point in $\overline{\mathrm{B}_{\mathrm{d}_{l}}\left(\mathrm{x}_{0}, \mathrm{r}\right)}$ and $\left\{\mathrm{x}_{\mathrm{n}}\right\}$ be a Picard sequence in $\mathrm{X}$ with initial guess $\mathrm{x}_{0}$. Let $\alpha: \mathrm{X} \times \mathrm{X} \rightarrow[0,+\infty)$ be a semi $\alpha$-admissible mapping on $\overline{\mathrm{B}_{\mathrm{d}_{l}}\left(\mathrm{x}_{0}, \mathrm{r}\right)}$ with $\alpha\left(\mathrm{x}_{0}, \mathrm{x}_{1}\right) \geqslant 1$. For $\mathrm{a}, \mathrm{b} \in[0,1)$ with $\mathrm{a}+2 \mathrm{~b}<1$, assume that,

$$
x, y \in \overline{B_{d_{l}}\left(x_{0}, r\right)}, \alpha(x, y) \geqslant 1 \text {, implies } d_{l}(S x, S y) \leqslant a_{l}(x, y)+b\left[d_{l}(x, S x)+d_{l}(y, S y)\right]
$$

and

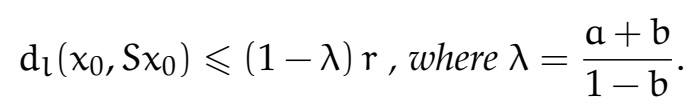

Then $\left\{x_{n}\right\}$ is a sequence in $\overline{\mathrm{B}_{\mathrm{d}_{l}}\left(\mathrm{x}_{0}, \mathrm{r}\right)}$ and $\mathrm{x}_{\mathrm{n}} \rightarrow x^{*} \in \overline{\mathrm{B}_{\mathrm{d}_{\mathrm{l}}}\left(\mathrm{x}_{0}, \mathrm{r}\right)}$ and $\alpha\left(\mathrm{x}_{\mathrm{n}}, \mathrm{x}_{\mathrm{n}+1}\right) \geqslant 1$ for all $\mathrm{n} \in \mathbb{N} \cup\{0\}$. Also, if $\alpha\left(x_{n}, x^{*}\right) \geqslant 1$ for all $n \in \mathbb{N} \cup\{0\}$, and inequality (2.7) holds for all $x, y \in\left(\overline{\mathrm{B}_{\mathrm{d}_{l}}\left(\mathrm{x}_{0}, \mathrm{r}\right)} \cap\left\{\mathrm{XS}\left(\mathrm{x}_{\mathrm{n}}\right)\right\}\right) \cup\left\{x^{*}\right\}$, then $x^{*}$

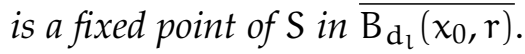

Recall that if $(X, \preceq)$ is a preordered set and $T: X \rightarrow X$ is such that for $x, y \in X$, with $x \preceq y$ implies $T x \preceq T y$, then the mapping $T$ is said to be non-decreasing.

Corollary 2.4. Let $\left(\mathrm{X}, \mathrm{d}_{\mathrm{l}}\right)$ be a complete dislocatedmetric space, $\mathrm{S}: \mathrm{X} \rightarrow \mathrm{X}$ be nondecreasing maping, $\mathrm{r}>0$ and $\mathrm{x}_{0}$ be an arbitrary point in $\overline{\mathrm{B}_{\mathrm{d}_{\mathrm{l}}}\left(\mathrm{x}_{0}, \mathrm{r}\right)},\left\{\mathrm{x}_{\mathrm{n}}\right\}$ be a Picard sequence in $\mathrm{X}$ with initial guess $\mathrm{x}_{0}$ and $\mathrm{x}_{0} \preceq \mathrm{x}_{1}$. For $\mathrm{a}, \mathrm{b} \in[0,1)$ with $\mathrm{a}+2 \mathrm{~b}<1$ such that

$$
d_{d_{l}}(S x, S y) \leqslant a d_{l}(x, y)+b\left[d_{l}(x, S x)+d_{l}(y, S y)\right]
$$

for all $x, y$ in $\overline{\mathrm{B}_{\mathrm{d}_{l}}\left(\mathrm{x}_{0}, \mathrm{r}\right)} \cap\left\{\mathrm{XS}\left(\mathrm{x}_{\mathrm{n}}\right)\right\}$ with $\mathrm{x} \preceq \mathrm{y}$, and

$$
d_{l}\left(x_{0}, S x_{0}\right) \leqslant(1-\lambda) r \text {, where } \lambda=\frac{a+b}{1-b} .
$$

Then $\left\{x_{n}\right\}$ is a sequence in $\overline{\mathrm{B}_{\mathrm{d}_{l}}\left(x_{0}, r\right)}, x_{n} \preceq x_{n+1}$ and $\left\{x_{n}\right\} \rightarrow x^{*} \in \overline{\mathrm{B}_{\mathrm{d}_{l}}\left(x_{0}, r\right)}$. Also if $x^{*} \preceq x_{n}$ or $x_{n} \preceq x^{*}$ for all $\mathrm{n} \in \mathbb{N} \cup\{0\}$ and inequality (2.8) holds for all $\mathrm{x}, \mathrm{y} \in\left(\overline{\mathrm{B}_{\mathrm{d}_{l}}\left(\mathrm{x}_{0}, \mathrm{r}\right)} \cap\left\{\mathrm{XS}\left(\mathrm{x}_{\mathrm{n}}\right)\right\}\right) \cup\left\{x^{*}\right\}$, then $x^{*}$ is a fixed point of $\mathrm{S}$ in $\overline{\mathrm{B}_{\mathrm{d}_{\mathrm{l}}}\left(\mathrm{x}_{0}, \mathrm{r}\right)}$.

Example 2.5. Let $X=R^{+} \cup\{0\}$ and let $d_{l}: X \times X \rightarrow X$ be the complete dislocated metric on $X$ defined by,

$$
d_{l}(x, y)=x+y \text { for all } x, y \in X .
$$

Define the multivalued mapping $S: X \rightarrow P(X)$ by

$$
S x= \begin{cases}{\left[\frac{2}{3} x, \frac{1}{2}\right],} & \text { if } x \in[0,1) \\ {[x, x+2],} & \text { if } x \in(1, \infty) .\end{cases}
$$


Consider $x_{0}=1, r=21, a=\frac{1}{2}, b=\frac{1}{5}$, then $\lambda=\frac{7}{8}, \overline{B_{d_{l}}\left(x_{0}, r\right)}=[0,20]$ and $(1-\lambda) r=\frac{5}{2}>d_{l}\left(x_{0}, S x_{0}\right)=\frac{5}{3}$.

So we obtain a sequence $\left\{X S\left(x_{n}\right)\right\}=\left\{1, \frac{2}{3}, \frac{4}{9}, \frac{8}{27}, \ldots\right\}$ in $X$ generated by $x_{0}$. Define the mapping,

$$
\alpha(x, y)= \begin{cases}1, & \text { if } x, y \in[0,1] \\ \frac{3}{2}, & \text { otherwise }\end{cases}
$$

Now,

$$
\alpha_{*}(S 4, S 6) H_{d_{l}}(S 4, S 6)=\left(\frac{3}{2}\right) 12>\frac{1}{2} d_{l}(4,6)+\frac{1}{5}\left[d_{l}(4, S 4)+d_{l}(6, S 6)\right]=9 .
$$

So the contractive condition does not hold on $X$. Clearly, the contractive condition does not hold for all $x, y \in X$ and for all $x, y \in \overline{B_{d_{l}}\left(x_{0}, r\right)}$. Now for all $x, y \in \overline{B_{d_{l}}\left(x_{0}, r\right)} \cap\left\{X S\left(x_{n}\right)\right\}$, we have

$$
\begin{aligned}
\alpha_{*}(S x, S y) H_{d_{l}}(S x, S y) & =1\left[\max \left\{\sup _{a \in S x} d_{l}(a, S y), \sup _{b \in S y} d_{l}(S x, b)\right\}\right] \\
& =\max \left\{\sup _{a \in S x} d_{l}\left(a,\left[\frac{2 y}{3}, \frac{3 y}{4}\right]\right), \sup _{b \in S y} d_{l}\left(\left[\frac{2 x}{3}, \frac{3 x}{4}\right], b\right)\right\} \\
& =\max \left\{d_{l}\left(\frac{3 x}{4},\left[\frac{2 y}{3}, \frac{3 y}{4}\right]\right), d_{l}\left(\left[\frac{2 x}{3}, \frac{3 x}{4}\right], \frac{3 y}{4}\right)\right\} \\
& =\max \left\{d_{l}\left(\frac{3 x}{4}, \frac{2 y}{3}\right), d_{l}\left(\frac{2 x}{3}, \frac{3 y}{4}\right)\right\} \\
& \left.=\max \left\{\frac{3 x}{4}+\frac{2 y}{3}, \frac{2 x}{3}+\frac{3 y}{4}\right)\right\} \\
& \leqslant \frac{5}{6} x+\frac{5}{6} y=\frac{1}{2}(x+y)+\frac{1}{5}\left[x+\frac{2 x}{3}+y+\frac{2 y}{3}\right] \\
& =\frac{1}{2}(x+y)+\frac{1}{5}\left[d_{l}\left(x,\left[\frac{2 x}{3}, \frac{3 x}{4}\right]\right)+d_{l}\left(y,\left[\frac{2 y}{3}, \frac{3 y}{4}\right]\right)\right] \\
& =a d_{l}(x, y)+b\left[d_{l}(x, S x)+d_{l}(y, S y)\right] .
\end{aligned}
$$

So the contractive condition holds on $\overline{\mathrm{B}_{\mathrm{d}_{l}}\left(\mathrm{x}_{0}, \mathrm{r}\right)} \cap\left\{\mathrm{XS}\left(\mathrm{x}_{n}\right)\right\}$. Hence all the conditions of Theorem 2.1 are satisfied. Now, we have $\left\{X S\left(x_{n}\right)\right\}$ is a sequence in $\overline{B_{d_{l}}\left(x_{0}, r\right)}, \alpha\left(x_{n}, x_{n+1}\right) \geqslant 1$ and $\left\{X S\left(x_{n}\right)\right\} \longrightarrow 0 \in$ $\overline{\mathrm{B}_{\mathrm{d}_{l}}\left(\mathrm{x}_{0}, r\right)}$. Also, $\alpha\left(x_{n}, 0\right) \geqslant 1$ or $\alpha\left(0, x_{n}\right) \geqslant 1$ for all $n \in \mathbb{N} \cup\{0\}$. Moreover, $S$ has a fixed point 0 .

\section{Fixed point results for graphic contractions}

Consistent with Jachymski [16], let $(X, d)$ be a metric space and $\Delta$ denotes the diagonal of the Cartesian product $X \times X$. Consider a directed graph $G$ such that the set $V(G)$ of its vertices coincides with $X$, and the set $E(G)$ of its edges contains all loops, i.e., $E(G) \supseteq \Delta$. We assume $G$ has no parallel edges, so we can identify $G$ with the pair $(V(G), E(G)$ ). Moreover, we may treat $G$ as a weighted graph (see [16]) by assigning to each edge the distance between its vertices. If $x$ and $y$ are vertices in a graph $G$, then a path in $G$ from $x$ to $y$ of length $N(N \in \mathbb{N})$ is a sequence $\left\{x_{i}\right\}_{i=0}^{N}$ of $N+1$ vertices such that $x_{0}=x, x_{N}=y$ and $\left(x_{n-1}, x_{n}\right) \in E(G)$ for $i=1, \ldots, N$. A graph $G$ is connected if there is a path between any two vertices. $G$ is weakly connected if $\tilde{G}$ is connected (see for details $[10,11,16]$ ).

Definition 3.1 ([31]). Let $X$ be a nonempty set and $G=(V(G), E(G))$ be a graph such that $V(G)=X$, and let $\mathrm{T}: \mathrm{X} \rightarrow \mathrm{CB}(\mathrm{X})$. $\mathrm{T}$ is said to be graph preserving if it satisfies the following:

- if $(x, y) \in E(G)$, then $(u, v) \in E(G)$ for all $u \in T x$ and $v \in T y$.

In this section, we give fixed point results on a dislocated metric space endowed with a graph. 


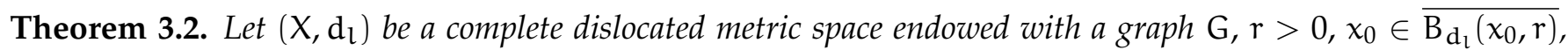
$\mathrm{S}: \mathrm{X} \rightarrow \mathrm{P}(\mathrm{X})$ and $\left\{\mathrm{XS}\left(\mathrm{x}_{\mathrm{n}}\right)\right\}$ be a sequence in $\mathrm{X}$ generated by $\mathrm{x}_{0}$ with $\left(\mathrm{x}_{0}, \mathrm{x}_{1}\right) \in \mathrm{E}(\mathrm{G})$. Assume the following conditions hold:

(i) $\mathrm{S}$ is graph preserving for all $\mathrm{x}, \mathrm{y} \in \overline{\mathrm{B}_{\mathrm{d}_{\mathrm{l}}}\left(\mathrm{x}_{0}, \mathrm{r}\right)}$,

(ii) there exist $a, b \in[0,1)$ with $a+2 b<1$, such that

$$
H_{d_{l}}(S x, S y) \leqslant a_{l}(x, y)+b\left[d_{l}(x, S x)+d_{l}(y, S y)\right]
$$

for all $x, y \in \overline{\mathrm{B}_{\mathrm{d}_{\mathrm{l}}}\left(\mathrm{x}_{0}, \mathrm{r}\right)} \cap\left\{\mathrm{XS}\left(\mathrm{x}_{\mathrm{n}}\right)\right\}$ and $(\mathrm{x}, \mathrm{y}) \in \mathrm{E}(\mathrm{G})$,

(iii) there exists $x_{0} \in \overline{B_{d_{l}}\left(x_{0}, r\right)}$, such that $d_{l}\left(x_{0}, S x_{0}\right) \leqslant(1-\lambda) r$, where $\lambda=\frac{a+b}{1-b}$.

Then $\left\{\mathrm{XS}\left(\mathrm{x}_{\mathrm{n}}\right)\right\}$ is a sequence in $\overline{\mathrm{B}_{\mathrm{d}_{l}}\left(\mathrm{x}_{0}, \mathrm{r}\right)},\left(\mathrm{x}_{\mathrm{n}}, \mathrm{x}_{\mathrm{n}+1}\right) \in \mathrm{E}(\mathrm{G})$ and $\left\{\mathrm{XS}\left(\mathrm{x}_{\mathrm{n}}\right)\right\} \rightarrow \mathrm{x}^{*}$. Also if $\left(\mathrm{x}_{\mathrm{n}}, \mathrm{x}^{*}\right) \in \mathrm{E}(\mathrm{G})$ or $\left(x^{*}, x_{n}\right) \in E(G)$ for all $n \in \mathbb{N} \cup\{0\}$ and inequality (3.1) holds for all $x, y \in\left(\overline{B_{d_{l}}\left(x_{0}, r\right)} \cap\left\{X S\left(x_{n}\right)\right\}\right) \cup\left\{x^{*}\right\}$, then $x^{*}$ is a fixed point of $\mathrm{S}$ in $\overline{\mathrm{B}_{\mathrm{d}_{\mathrm{l}}}\left(\mathrm{x}_{0}, \mathrm{r}\right)}$.

Proof. Define $\alpha: X \times X \rightarrow[0,+\infty)$ by

$$
\alpha(x, y)= \begin{cases}1, & \text { if }(x, y) \in E(G) \\ 0, & \text { otherwise }\end{cases}
$$

As $\left\{X S\left(x_{n}\right)\right\}$ is a sequence in $X$ generated by $x_{0}$ with $\left(x_{0}, x_{1}\right) \in E(G)$, we have $\alpha\left(x_{0}, x_{1}\right) \geqslant 1$. Let, $\alpha(x, y) \geqslant 1$, then $(x, y) \in E(G)$. From (i), we have $(u, v) \in E(G)$ for all $u \in S x$ and $v \in S y$. This implies that $\alpha(u, v)=1$ for all $u \in S x$ and $v \in S y$. This further implies that $\inf \{\alpha(u, v): u \in S x, v \in S y\}=1$. Thus $S$ is a semi $\alpha_{*}$-admissible multifunction on $\overline{\mathrm{B}_{\mathrm{d}_{l}}\left(x_{0}, r\right)}$. Also, if $(x, y) \in E(G)$, we have $\alpha(x, y)=1$ and hence, $\alpha_{*}(\mathrm{~S} x, \mathrm{Sy})=1$. Now, condition (ii) can be written as

$$
\alpha_{*}(S x, S y) H_{d_{l}}(S x, S y)=H_{d_{l}}(S x, S y) \leqslant a d_{l}(x, y)+b\left[d_{l}(x, S x)+d_{l}(y, S y)\right]
$$

for all $x, y \in \overline{\mathrm{B}_{\mathrm{d}_{\mathrm{l}}}\left(\mathrm{x}_{0}, r\right)} \cap\left\{\mathrm{XS}\left(\mathrm{x}_{\mathrm{n}}\right)\right\}$. By including condition (iii) we obtain all the conditions of Theorem 2.1 are satisfied. Now, by Theorem 2.1, we have $\left\{X S\left(x_{n}\right)\right\}$ is a sequence in $\overline{B_{d_{l}}\left(x_{0}, r\right)}, \alpha\left(x_{n}, x_{n+1}\right) \geqslant 1$, that is, $\left(x_{n}, x_{n+1}\right) \in E(G)$ and $\left\{X S\left(x_{n}\right)\right\} \rightarrow x^{*} \in \overline{B_{d_{l}}\left(x_{0}, r\right)}$. Also if $\left(x_{n}, x^{*}\right) \in E(G)$ or $\left(x^{*}, x_{n}\right) \in E(G)$ for all $n \in$ $\mathbb{N} \cup\{0\}$ and inequality (3.1) holds for all $x, y \in\left(\overline{B_{d_{l}}\left(x_{0}, r\right)} \cap\left\{X S\left(x_{n}\right)\right\}\right) \cup\left\{x^{*}\right\}$, then, we have $\alpha\left(x_{n}, x^{*}\right) \geqslant 1$ or $\alpha\left(x^{*}, x_{n}\right) \geqslant 1$ for all $n \in \mathbb{N} \cup\{0\}$ and inequality (2.1) holds for all $x, y \in\left(\overline{B_{d_{l}}\left(x_{0}, r\right)} \cap\left\{X S\left(x_{n}\right)\right\}\right) \cup\left\{x^{*}\right\}$. Again, by Theorem 2.1, $S$ has a fixed point $x^{*}$ in $\overline{\mathrm{B}_{\mathrm{d}_{\mathrm{l}}}\left(\mathrm{x}_{0}, \mathrm{r}\right)}$.


$\mathrm{S}: \mathrm{X} \rightarrow \mathrm{P}(\mathrm{X})$ and $\left\{\mathrm{XS}\left(\mathrm{x}_{\mathrm{n}}\right)\right\}$ be a sequence in $\mathrm{X}$ generated by $\mathrm{x}_{0}$ with $\left(\mathrm{x}_{0}, \mathrm{x}_{1}\right) \in \mathrm{E}(\mathrm{G})$. Assume the following conditions hold:

(i) $\mathrm{S}$ is graph preserving for all $\mathrm{x}, \mathrm{y} \in \overline{\mathrm{B}_{\mathrm{d}_{\mathrm{l}}}\left(\mathrm{x}_{0}, \mathrm{r}\right)}$;

(ii) there exists $b \in\left[0, \frac{1}{2}\right)$, such that

$$
\mathrm{H}_{\mathrm{d}_{l}}(S x, S y) \leqslant b\left[d_{l}(x, S x)+d_{l}(y, S y)\right]
$$

for all $x, y \in \overline{\mathrm{B}_{\mathrm{d}_{\mathrm{l}}}\left(\mathrm{x}_{0}, \mathrm{r}\right)} \cap\left\{\mathrm{XS}\left(\mathrm{x}_{\mathrm{n}}\right)\right\}$ and $(\mathrm{x}, \mathrm{y}) \in \mathrm{E}(\mathrm{G})$;

(iii) there exists $x_{0} \in \overline{B_{d_{l}}\left(x_{0}, r\right)}$, such that $d_{l}\left(x_{0}, S x_{0}\right) \leqslant(1-\lambda) r$, where $\lambda=\frac{b}{1-b}$.

Then $\left\{\mathrm{XS}\left(\mathrm{x}_{\mathrm{n}}\right)\right\}$ is a sequence in $\overline{\mathrm{B}_{\mathrm{d}_{l}}\left(\mathrm{x}_{0}, \mathrm{r}\right)},\left(\mathrm{x}_{\mathrm{n}}, \mathrm{x}_{\mathrm{n}+1}\right) \in \mathrm{E}(\mathrm{G})$ and $\left\{\mathrm{XS}\left(\mathrm{x}_{\mathrm{n}}\right)\right\} \rightarrow \mathrm{x}^{*}$. Also if $\left(\mathrm{x}_{\mathrm{n}}, \mathrm{x}^{*}\right) \in \mathrm{E}(\mathrm{G})$ or $\left(x^{*}, x_{n}\right) \in E(G)$ for all $n \in \mathbb{N} \cup\{0\}$ and inequality (3.2) holds for all $x, y \in\left(\overline{\mathrm{B}_{\mathrm{d}_{l}}\left(\mathrm{x}_{0}, r\right)} \cap\left\{\mathrm{XS}\left(\mathrm{x}_{\mathrm{n}}\right)\right\}\right) \cup\left\{\mathrm{x}^{*}\right\}$, then $x^{*}$ is a fixed point of $\mathrm{S}$ in $\overline{\mathrm{B}_{\mathrm{d}_{l}}\left(\mathrm{x}_{0}, \mathrm{r}\right)}$. 
Proof. In Theorem 3.2, take $\mathrm{a}=0$ to get fixed point $x^{*} \in \overline{\mathrm{B}\left(\mathrm{x}_{0}, \mathrm{r}\right)}$ such that $x^{*} \in \mathrm{S} x^{*}$.

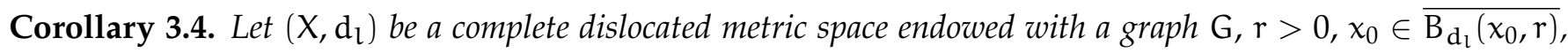
$\mathrm{S}: \mathrm{X} \rightarrow \mathrm{P}(\mathrm{X})$ and $\left\{\mathrm{XS}\left(\mathrm{x}_{\mathrm{n}}\right)\right\}$ be a sequence in $\mathrm{X}$ generated by $\mathrm{x}_{0}$ with $\left(\mathrm{x}_{0}, \mathrm{x}_{1}\right) \in \mathrm{E}(\mathrm{G})$. Assume the following conditions hold:

(i) $S$ is graph preserving for all $x, y \in \overline{\mathrm{B}_{\mathrm{d}_{\mathrm{l}}}\left(\mathrm{x}_{0}, \mathrm{r}\right)}$,

(ii) there exists a $\in[0,1)$, such that

$$
H_{d_{l}}(S x, S y) \leqslant \operatorname{ad}_{l}(x, y)
$$

for all $x, y \in \overline{B_{d_{l}}\left(x_{0}, r\right)} \cap\left\{X S\left(x_{n}\right)\right\}$ and $(x, y) \in E(G)$,

(iii) there exists $x_{0} \in \overline{B_{d_{l}}\left(x_{0}, r\right)}$, such that $d_{l}\left(x_{0}, S x_{0}\right) \leqslant(1-a) r$.

Then $\left\{\mathrm{XS}\left(\mathrm{x}_{\mathrm{n}}\right)\right\}$ is a sequence in $\overline{\mathrm{B}_{\mathrm{d}_{l}}\left(\mathrm{x}_{0}, \mathrm{r}\right)},\left(\mathrm{x}_{\mathrm{n}}, \mathrm{x}_{\mathrm{n}+1}\right) \in \mathrm{E}(\mathrm{G})$ and $\left\{\mathrm{XS}\left(\mathrm{x}_{\mathrm{n}}\right)\right\} \rightarrow \mathrm{x}^{*}$. Also if $\left(\mathrm{x}_{\mathrm{n}}, \mathrm{x}^{*}\right) \in \mathrm{E}(\mathrm{G})$ or $\left(x^{*}, x_{n}\right) \in E(G)$ for all $n \in \mathbb{N} \cup\{0\}$ and inequality (3.3) holds for all $x, y \in\left(\overline{\mathrm{B}_{\mathrm{d}_{l}}\left(\mathrm{x}_{0}, \mathrm{r}\right)} \cap\left\{\mathrm{XS}\left(\mathrm{x}_{\mathrm{n}}\right)\right\}\right) \cup\left\{\mathrm{x}^{*}\right\}$, then $x^{*}$ is a fixed point of $S$ in $\overline{\mathrm{B}_{\mathrm{d}_{l}}\left(\mathrm{x}_{0}, \mathrm{r}\right)}$.

Proof. In Theorem 3.2, take $\mathrm{b}=0$ to get fixed point $x^{*} \in \overline{\mathrm{B}\left(\mathrm{x}_{0}, \mathrm{r}\right)}$ such that $x^{*} \in \mathrm{S} x^{*}$.

Remark 3.5. We can obtain the metric version of all the theorems which are still not presented in the literature.

\section{Acknowledgment}

The authors sincerely thank the learned referee for a careful reading and thoughtful comments. The present version of the paper owes much to the precise and kind remarks of anonymous referees.

\section{References}

[1] M. U. Ali, T. Kamran, On $\left(\alpha^{*}, \psi\right)$-contractive multi-valued mappings, Fixed Point Theory Appl., 2013 (2013), 7 pages. 1

[2] A Amini-Harandi, Metric-like spaces, partial metric spaces and fixed points, Fixed Point Theory Appl., 2012 (2012), 10 pages. 1

[3] M. Arshad, A. Azam, M. Abbas, A. Shoaib, Fixed points results of dominated mappings on a closed ball in ordered partial metric spaces without continuity, Politehn. Univ. Bucharest Sci. Bull. Ser. A Appl. Math. Phys., 76 (2014), 123-134. 1

[4] M. Arshad, A. Shoaib, M. Abbas, A. Azam, Fixed points of a pair of Kannan type mappings on a closed ball in ordered partial metric spaces, Miskolc Math. Notes, 14 (2013), 769-784.

[5] M. Arshad, A. Shoaib, I. Beg, Fixed point of a pair of contractive dominated mappings on a closed ball in an ordered dislocated metric space, Fixed Point Theory Appl., 2013 (2013), 15 pages. 1, 1.1, 1.2, 1.3

[6] M. Arshad, A. Shoaib, P. Vetro, Common fixed points of a pair of Hardy Rogers type mappings on a closed ball in ordered dislocated metric spaces, J. Funct. Spaces Appl., 2013 (2013), 9 pages. 1

[7] J. H. Asl, S. Rezapour, N. Shahzad, On fixed points of $\alpha-\psi$-contractive multifunctions, Fixed Point Theory Appl., 2012 (2012), 6 pages. 1

[8] A. Azam, M. Arshad, Fixed points of a sequence of locally contractive multivalued maps, Comput. Math. Appl., 57 (2009), 96-100. 1

[9] A. Azam, N. Mehmood, J. Ahmad, S. Radenović, Multivalued fixed point theorems in cone b-metric spaces, J. Inequal. Appl., 2013 (2013), 9 pages. 1

[10] F. Bojor, Fixed point theorems for Reich type contractions on metric spaces with a graph, Nonlinear Anal., 75 (2012), 3895-3901. 3

[11] R. Espínola, W. A. Kirk, Fixed point theorems in R-trees with applications to graph theory, Topology Appl., 153 (2006), 1046-1055. 3

[12] P. Hitzler, A. K. Seda, Dislocated topologies, J. Electr. Eng., 51 (2000), 3-7. 1

[13] N. Hussain, J. Ahmad, A. Azam, Generalized fixed point theorems for multi-valued $\alpha$ - $\psi$-contractive mappings, J. Inequal. Appl., 2014 (2014), 15 pages. 1

[14] N. Hussain, M. Arshad, A. Shoaib, Fahimuddin, Common fixed point results for $\alpha$ - $\psi$-contractions on a metric space endowed with graph, J. Inequal. Appl., 2014 (2014), 14 pages. 1

[15] N. Hussain, P. Salimi, A. Latif, Fixed point results for single and set-valued $\alpha-\eta-\psi$-contractive mappings, Fixed Point Theory Appl., 2013 (2013), 23 pages. 1 
[16] J. Jachymski, The contraction principle for mappings on a metric space with a graph, Proc. Amer. Math. Soc., 136 (2008), 1359-1373. 3

[17] E. Karapınar, P. Salimi, Dislocated metric space to metric spaces with some fixed point theorems, Fixed Point Theory Appl., 2013 (2013), 19 pages. 1, 1.1

[18] M. A. Kutbi, M. Arshad, A. Hussain, On modified ( $\alpha-\eta)$-contractive mappings, Abstr. Appl. Anal., 2014 (2014), 7 pages. 1

[19] S. G. Matthews, Partial metric topology, Papers on general topology and applications, Flushing, NY, (1992), Ann. New York Acad. Sci., New York Acad. Sci., New York, 728 (1994), 183-197. 1

[20] S. B. Nadler, Jr., Multi-valued contraction mappings, Pacific J. Math., 30 (1969), 475-488. 1

[21] M. Nazam, M. Arshad, On a fixed point theorem with application to integral equations, Int. J. Anal., 2016 (2016), 7 pages. 1

[22] M. Nazam, M. Arshad, M. Abbas, Some fixed point results for dualistic rational contractions, Appl. Gen. Topol., 17 (2016), 199-209. 1

[23] M. Nazam, M. Arshad, C. Park, Fixed point theorems for improved $\alpha$-Geraghty contractions in partial metric spaces, J. Nonlinear Sci. Appl., 9 (2016), 4436-4449. 1

[24] S. Reich, Some remarks concerning contraction mappings, Canad. Math. Bull., 14 (1971), 121-124. 1

[25] Y.-J. Ren, J.-L. Li, Y.-R. Yu, Common fixed point theorems for nonlinear contractive mappings in dislocated metric spaces, Abstr. Appl. Anal., 2013 (2013), 5 pages. 1

[26] B. Samet, M. Rajović, R. Lazović, R. Stojiljković, Common fixed-point results for nonlinear contractions in ordered partial metric spaces, Fixed Point Theory Appl., 2011 (2011), 14 pages. 1

[27] B. Samet, C. Vetro, P. Vetro, Fixed point theorems for $\alpha \psi$-contractive type mappings, Nonlinear Anal., 75 (2012), 2154-2165. 1

[28] A. Shoaib, M. Arshad, J. Ahmad, Fixed point results of locally contractive mappings in ordered quasi-partial metric spaces, Scientific World J., 2013 (2013), 8 pages. 1

[29] A. Shoaib, M. Arshad, A. Azam, Fixed points of a pair of locally contractive mappings in ordered partial metric spaces, Mat. Vesnik, 67 (2015), 26-38.

[30] A. Shoaib, M. Arshad, M. A. Kutbi, Common fixed points of a pair of Hardy Rogers type mappings on a closed ball in ordered partial metric spaces, J. Comput. Anal. Appl., 17 (2014), 255-264. 1

[31] J. Tiammee, S. Suantai, Coincidence point theorems for graph-preserving multi-valued mappings, Fixed Point Theory Appl., 2014 (2014), 11 pages. 3.1 